\title{
On Intertextuality Theory and English Translation Practice
}

\author{
Zonghua Zhu \\ Dalian Economic Cooperation Service Center, Dalian 116001, Liaoning, China
}

\begin{abstract}
Under the background of economic globalization, the cultures between my country and other countries are showing a trend of mutual integration. In our country, the intertextuality theory is used to guide English translation in the English education model of all classes. The application of intertextuality theory can help students understand the meaning of English more clearly. The organic combination of intertextuality theory and English translation practice can effectively help students gain a deeper grasp of English translation skills and guide students to ingeniously integrate different languages and cultures.
\end{abstract}

Keywords: Intertextuality Theory; English Translation; Organic Integration; Practice

Intertextuality theory can promote the smooth development of students'English translation practice to a certain extent. Teachers should make full use of intertextuality theory to teach, use intertextuality theory to promote students'English translation level, and give full play to students'learning in class. The main body status in the Chinese language, cultivate students' independent research and thinking ability and consciousness, in order to help students consciously use intertextuality theory to optimize their own translation context and improve the accuracy of English translation.

\section{The concept of intertextuality theory}

(1) Intertextuality theory is a new type of civilization theory emerging at this stage in our country. It was first used by French semiotics. Intertextuality refers to texts that exist in other texts, and there are certain connections between different texts. Intertextuality theory inherits the advantages of structuralism, and draws on the strengths of traditional deconstructionism and postmodernism. It conforms to the development trend of modern text theory in my country and has received widespread attention.

(2) Intertextuality theory breaks through the limitations of traditional art theory research and critical terminology, and is very inclusive and expandable. This theory plays a very important role in the field of literature. The context of intertextuality theory transforms political, historical, social, and psychological elements into intertextuality, breaking the shackles of traditional literary concepts to a certain extent, and has very strong development potential.

(3) The continuous advancement and deepening of intertextuality theory at the cultural level has promoted the development of literature in a more ideological direction. Second, the multiple and complex unity between different text structures has promoted the polyphonic nature of literary creation.

\section{Intertextual reference and intertextual marking}

Intertextual reference (cultural structure and cultural connotation) and intertextual marking (the organic part of the text) are the key factors affecting intertextuality. Intertextual reference and intertextual marking interact and complement each other. The intertextual mark often represents the author's intention in writing. Translators should evaluate the previous text at the three levels of communication, language and symbols based on the determined intertextuality, so as to translate literary works on the basis of preserving the original text.

\section{Intertextuality theory and English translation practice}

\subsection{The translator, as a reader, must intertextually interpret the original text}

The translator first reads and understands the text repeatedly as a reader, fully grasps the intertextual reference of the text, and captures the thoughts and feelings of the literary creator through the surface of the text language. Intertextual interpretation of the original text can help Readers have a better understanding of the connotation expressed in the text. Intertextuality, as the first of the five types of texts, refers to making full use of methods such as citation and suggestion to present one text in another text. The two texts are in a cooperative and coexisting relationship. Experienced translators will fully grasp and use the spanning relationship, and interpret the original version with purpose and pertinence. Translators must deconstruct the complex original text, understand

Copyright (C) 2020 Zonghua Zhu

doi: 10.18282/l-e.v9i2.1383

This is an open-access article distributed under the terms of the Creative Commons Attribution Non-Commercial License

(http://creativecommons.org/licenses/by-nc/4.0/), which permits unrestricted non-commercial use, distribution, and reproduction in any medium, provided the original work is properly cited. 
the sentiments of the author expressed in literary works, refer to relevant documents and materials to distribute the text, and be careful not to change the author's true thoughts and intentions.

\subsection{The translator, as the author, should intertextually write the original text}

In the process of writing, translators must organically integrate the two texts based on the intertextuality between them. Before writing, they must carefully grasp the original text, grasp the ideological intention and purpose of the author of the text. The central meaning cannot be changed.

\subsection{Implement open teaching}

English translation is an activity that intertextualizes different languages and cultures. It has the characteristics of professionalism and practicability. The application of open teaching concepts and models to teaching can break the limitations of the original text and give full play to students and teachers in the whole The dual subject function in the education process optimizes the combination of existing teaching resources according to factors such as text type, genre and language sense, and provides students with a broader space for development. Teachers should also give students sufficient time and space to conduct group cooperative inquiry learning, create English translation context according to their own actual conditions, guide and encourage students to express their own unique opinions, and then summarize and summarize students' views, so as to improve students' sense of cooperation and independent inquiry ability.

\subsection{The translator needs to dynamically convert the original text from multiple angles}

English translation is a dynamic and creative activity that requires multiple transformations from different cultures in the process of practice. Relying on the theory of intertextuality and combining actual development, it will conduct research from the three aspects of the original text author, translator and reader, Complete the intertextual activities. In daily learning, teachers should guide students to interact with different cultures in the course of business activities, cultivate students' translation ability, grasp translation skills, and strengthen students' understanding and feeling ability.

\subsection{Cultivate divergent thinking appropriately}

The intertextuality theory explains the translator's understanding of the original text from a new perspective.

Properly cultivating students' divergent thinking can stimulate students' initiative and creativity in English translation.

Promote students to find problems in practice and find appropriate methods to solve them. Teachers should create different contexts for students and actively guide students to elaborate from multiple levels and texts.

\section{Conclusion}

In summary, the research field of English language cannot be separated from the intertextuality of text. Intertextuality includes two aspects: register and intertextual analysis, which can promote the fusion of modern literary media. Intertextuality theory can help students better perform English translation. Teachers should focus on intertextuality theory in the teaching process. Use, appropriately let students conduct intertextual analysis of the text, and promote students to better construct their own text.

\section{References}

1. Zhou Chun. Intertextuality Theory and English Translation Practice Research [J]. Talent, 2020(16): 230.

2. Ye Xiaoling. A Study of Specific Intertextuality in Chinese Middle School Students' English Compositions [D]. Jimei University, 2019.

3. Guan Changping. Application analysis of intertextuality theory in English translation [J]. Journal of Jiamusi Vocational College, 2017(07): 390 . 